\title{
Transmission of drug-resistant HIV-1 in Europe remains limited to single classes
}

\section{The SPREAD programme*}

Background: The spread of drug-resistant HIV-1 might compromise the future success of current first-line regimens.

Objective: To analyse the extent and impact of transmission of drug-resistant HIV-1 variants in Europe.

Design and methods: The European prospective programme (SPREAD) collected demographic, clinical and virological data from 1245 HIV-1-infected individuals in 17 countries diagnosed in 2002-2003. The potential impact of transmitted drug resistance mutations (TDRMs) on therapy response was determined by using genotypic interpretation algorithms.

Results: The overall prevalence of viruses with drug-resistance mutations was $9.1 \%$ [96/1050; 95\% confidence interval: 7.5-11.1]. The majority (71\%) harboured only a single amino acid substitution with limited effect on predicted drug susceptibility. Mutations associated with resistance to nucleoside reverse transcriptase inhibitors were observed most frequently [57/1050 (5.4\%)], followed by mutations related to protease inhibitors [32/1050 (3.0\%)] and mutations related to non-nucleoside reverse transcriptase inhibitors (NNRTIs) [27/1050 (2.6\%)].

In some cases, however, resistance was quite extensive. Four individuals were infected with viruses with reduced susceptibility to all nucleoside reverse transcriptase inhibitors, 3 to all protease inhibitors and 20 to both NNRTIs. Remarkably, in one individual, the resistance pattern was so extensive that none of the available current antiretroviral drugs was predicted to be fully active.

Conclusion: The prevalence of TDRM-HIV is quite prominent $(9.1 \%)$ but did not increase in comparison with a large retrospective European study. Particularly the presence of single NNRTI mutations may impact the efficacy of the first-line regimens. Continuous prospective monitoring remains indicated to explore the patterns and factors contributing to the transmission of TDRMs as well as the potential clinical consequences.

(c) 2008 Wolters Kluwer Health | Lippincott Williams \& Wilkins

AIDS 2008, 22:625-635

Keywords: Europe, HIV-1, resistance, transmission

\section{Introduction}

Combinations of the more recently approved highly active antiretroviral drugs have been shown to be capable of successful long-term suppression of viral replication in the majority of HIV-1-infected patients. Nevertheless, emergence of viral variants with reduced susceptibility to drugs remains an important cause of treatment failure. Loss of control of viral replication during therapy has been associated with an increased risk of transmission of
HIV-1 [1,2]. Indeed, the presence of drug-resistant variants in newly diagnosed individuals indicates that a proportion of individuals with treatment failure continue to engage in risk-related behaviour, despite awareness of their HIV-positive status [3].

Although several reports have been published on the spread of drug-resistant viruses in treatment-naive individuals, most studies have limited value, as they are retrospective and based on convenience sampling. To

Correspondence to Charles A.B. Boucher, MD, PhD, Department of Virology, Eijkman Winkler Institute, University Medical Centre Utrecht, Utrecht, The Netherlands.

Tel: +31 30 2506526; fax: +31 30 2505426; e-mail: a.m.j.wensing@umcutrecht.nl

* See the list of members in Acknowledgements.

Received: 5 March 2007; revised: 9 October 2007; accepted: 12 October 2007. 
date, only a few prospective studies limited to single countries have been published $[4,5]$. None of the current studies reflects the overall European situation that is characterized by the presence of all relevant transmission groups, men having sex with men, intravenous drug users, heterosexuals and a large proportion of individuals infected in resource-limited countries.

We set up the SPREAD surveillance programme as a prospective monitoring programme to collect the representative data on the spread of resistance among newly diagnosed patients from all risk groups and to estimate the dynamics of the spread of drug-resistant HIV-1 among the approximately 30000 newly diagnosed individuals each year in Western Europe [6]. Public health institutes and academic centres from 33 countries across Europe participate in the programme (www.SPREADeurope.org). We present the results of the first round of data collected from 17 countries.

\section{Methods}

\section{Data collection}

Newly diagnosed HIV-1-infected individuals of age 18 years and older who had never been exposed to antiretroviral drugs were prospectively recruited. Sampling took place in 16 European countries and Israel. A standardized sampling strategy was designed by the epidemiology expert group of the SPREAD programme to ensure representative sampling in all countries. In summary, in countries where more than $80 \%$ of all newly diagnosed individuals were expected to be covered by the participating centres (Austria, Denmark, Finland, Greece, Ireland, Israel, Luxembourg, Norway, Serbia Montenegro and Sweden), a random sample from all newly identified individuals was taken. In other countries (Belgium, Germany, Italy, the Netherlands, Poland, Portugal and Spain), stratified sampling weighted for the proportion of newly diagnosed patients among different risk groups and among different geographical areas was performed or the first consecutive number of patients up to a predefined number per geographic region was included $[7,8]$. Importantly, the sampling strategies were defined in close collaboration with the involved national public health institutes that had access to the latest information on national HIV epidemics. Sample sizes were weighted per country according to the HIV-1 prevalence and based on the calculation that at least 916 individuals were needed to enable detection of an increase in the prevalence over time from 10 to $15 \%$ (power of $90 \%, \alpha$ of $5 \%$ ) for future analyses of different collection rounds $[7,8]$.

Epidemiological, clinical and virological data were collected using a comprehensive standardized questionnaire. HIV-RNA plasma levels were collected within 3 months of diagnosis. Newly diagnosed individuals were defined as recently infected if they had documented negative or indeterminate HIV-1 serological results up to 12 months prior to confirmation of diagnosis by western blot. The remaining newly diagnosed individuals were classified as those with undefined duration of infection. Non-European countries were classified as highprevalence countries if the prevalence of HIV-1 in the population was greater than $1 \%$, as defined by UNAIDS [9].

\section{Patient population}

Data from 1245 HIV-1-infected individuals who were newly diagnosed between September 2002 and December 2003 were recorded. Based on the predefined strict entry criteria, 162 individuals could not be included: 24 because of HIV-RNA levels below 1000 copies/ml within 3 months of diagnosis, 130 because no HIV-RNA quantification was performed within 3 months of diagnosis, four because of the absence of confirmatory HIV-1 testing within 6 months and four because of possible therapy exposure. Comparison of the excluded and included set showed a difference in proportion of intravenous drug users $(21.0 \%, 34 / 162$ vs. $8.9 \%$, 96/ 1083) and the proportion of individuals from highprevalence countries $(9.3 \%, 15 / 162$ vs. $15.8 \%, 171 / 1083)$.

\section{Procedures}

The first available plasma sample obtained within 3 months of HIV-1 diagnosis was used for genotypic resistance analysis. Population-based nucleotide sequence analysis of the HIV-1 pol [protease and reverse transcriptase (RT)] gene was successfully performed on 97\% (1050/1083) of the samples. For this reason, the denominator for all further analyses was 1050 . Sequences were generated by local laboratories using either in-house methods or commercially available kits. All laboratories participated in a continuous blinded quality control programme to verify the quality of the data. Sequence alignment was performed with Clustal X (version 1.81; available at http://bips.u-strasbg.fr/fr/Documentation/ ClustalX/) [10].

Transmitted drug resistance mutations (TDRMs) were defined as the presence of at least one of the following mutations in protease: $30 \mathrm{~N}, 46 \mathrm{I} / \mathrm{L}, 48 \mathrm{~V}, 50 \mathrm{~L} / \mathrm{V}, 82 \mathrm{~A} / \mathrm{F} /$ $\mathrm{T} / \mathrm{S}, 84 \mathrm{~A} / \mathrm{C} / \mathrm{V}, 90 \mathrm{M}$; or RT: 41L, 44D, 62V, 65R, 67N, 69D/insert, 70R, 74V, 75I, 77L, 100I, 103N, 106A/M, 108I, 115F, 116Y, 151M, 181C/I, 184I/V, 188C/H/L, 190A/S, 210W, 215Y/F, 215 revertants A/C/D/E/G/ $\mathrm{H} / \mathrm{I} / \mathrm{L} / \mathrm{N} / \mathrm{S} / \mathrm{V}, 219 \mathrm{Q} / \mathrm{E}, 225 \mathrm{H}, 230 \mathrm{~L} ， 236 \mathrm{~L}$. These changes have been identified as related to drug resistance according to the list of mutations of the International AIDS Society USA (IAS-USA) [11]. Other resistancerelated mutations in the IAS list which are also known to appear as natural polymorphisms in wild-type HIV-1 (WT-HIV) were excluded as evidence of transmission of resistance. Amino acid changes conferred by the recently approved fusion inhibitor enfuvirtide were also not taken 
into account. Mixtures are those of wild-type virus and mutant(s) at a particular codon. Revertants are mutations on position 215 that commonly evolve from the $215 \mathrm{Y} / \mathrm{F}$ resistance mutations following withdrawal of drug selective pressure due to treatment interruption or transmission.

Viral subtypes were assessed on the basis of the pol sequence by using the REGA HIV-1 subtyping tool version 1.0 [12].

We predicted the potential impact of transmitted drug resistance on therapy response by analysing the genotype results using the following interpretation algorithms: the Rega resistance interpretation algorithm (version 6.4.1), the Agence Nationale de Recherches sur le Sida (ANRS) algorithm (version 2005.07; http://hivfrenchresistance.org) and the Stanford drug resistance algorithm (version 4.1.9) [13,14]. The overall predicted susceptibility as estimated by all the three algorithms was very similar (pair-wise $\kappa$ values exceed 0.6; data not shown). The data in Tables 2 and 3, therefore, refer only to the Rega algorithm.

\section{Statistical methods}

The prevalence of transmission of resistance was calculated with a 95\% confidence interval (CI) based on the binomial distribution. Categorical data were compared using $\chi^{2}$-test or Fisher's exact test if appropriate. Continuous data were investigated by means of a $t$-test or the Mann-Whitney $U$-test. Logistic regression analysis was used to examine the association between epidemiological, clinical and virological factors.

\section{Results}

A total of 1050 newly diagnosed HIV-1-infected individuals were enrolled of which $22 \%$ had laboratory evidence of recent infection ( $<1$ year). The majority of the individuals $(86.3 \%)$ contracted HIV-1 through sexual contact. Most them were infected with subtype B virus [690/1050 (65.7\%)] (Table 1). Furthermore, 12 non-B subtypes and circulating recombinant forms (CRFs) were identified based on the pol gene: A $9.4 \%$, C $8.7 \%$,

Table 1. Comparison of characteristics between patients infected with virus harbouring transmitted drug resistance mutations (TDRMs) and patients infected with wild-type virus.

\begin{tabular}{|c|c|c|c|c|c|}
\hline & Total & TDRM & Wild type & $P$ value & OR $(95 \% \mathrm{Cl})$ \\
\hline Patients $[n(\%)]^{\mathrm{a}}$ & 1050 & $96(9)$ & $954(91)$ & & \\
\hline Age [years, mean (SD)] & $37.1(11.1)$ & $37.3(10.9)$ & $37.1(11.1)$ & 0.847 & \\
\hline \multicolumn{6}{|l|}{$\operatorname{Sex}(\%)^{b}$} \\
\hline Male & $808(77)$ & $73(76)$ & $735(77)$ & 0.782 & $0.93(0.56-1.57)$ \\
\hline Female & $239(23)$ & $23(24)$ & $216(23)$ & & \\
\hline \multicolumn{6}{|l|}{ Area of origin $[n(\%)]^{\mathrm{c}}$} \\
\hline Western Europe & $694(67)$ & $67(72)$ & $627(66)$ & - & 1 \\
\hline Sub-Saharan Africa & $169(16)$ & $13(14)$ & $156(17)$ & 0.43 & $0.78(0.40-1.50)$ \\
\hline Eastern Europe and Central Asia & $94(9)$ & $9(10)$ & $85(9)$ & 0.98 & $0.99(0.44-2.15)$ \\
\hline Other & $83(8)$ & $4(4)$ & $79(8)$ & 0.15 & $0.47(0.14-1.40)$ \\
\hline \multicolumn{6}{|l|}{ Route of transmission $[n(\%)]^{\mathrm{d}}$} \\
\hline $\begin{array}{l}\text { Homo/bisexual contact } \\
\text { Heterosexual contact }\end{array}$ & $467(44)$ & $47(49)$ & $420(44)$ & - & 1 \\
\hline \multicolumn{6}{|l|}{ Heterosexual contact } \\
\hline Originating from or infected in HPC & $193(18)$ & $10(10)$ & $183(19)$ & 0.046 & $0.49(0.24-0.99)$ \\
\hline Other & $246(23)$ & $30(31)$ & $216(23)$ & 0.38 & $1.24(0.76-2.02)$ \\
\hline Injection drug use & $88(8)$ & $6(6)$ & $82(9)$ & 0.35 & $0.65(0.27-1.58)$ \\
\hline Other & $56(5)$ & $3(3)$ & $53(6)$ & 0.26 & $0.51(0.12-1.77)$ \\
\hline \multicolumn{6}{|l|}{ Duration of infection $[n(\%)]^{\mathrm{d}}$} \\
\hline$<1$ year & $235(22)$ & $25(26)$ & $210(22)$ & 0.37 & $1.25(0.77-2.02)$ \\
\hline Undefined & $815(78)$ & $71(74)$ & $744(78)$ & & \\
\hline \multicolumn{6}{|l|}{ CDC stage $[n(\%)]^{\mathrm{e}}$} \\
\hline$A$ and $B$ & $807(86)$ & $77(87)$ & $730(86)$ & 0.91 & $1.04(0.55-1.97)$ \\
\hline C & $130(14)$ & $12(14)$ & $118(14)$ & & \\
\hline CD4 cell count $[\text { cells } / \mu l \text {, median (range) }]^{f}$ & $330(1-1499)$ & $370(2-1488)$ & $328(1-1499)$ & 0.49 & \\
\hline HIV-RNA [log copies/ml, mean (SD)] $]^{d}$ & $4.83(0.8)$ & $4.75(0.8)$ & $4.85(0.8)$ & 0.22 & \\
\hline Subtype B $[n(\%)]^{\mathrm{g}}$ & $690(67)$ & $72(77)$ & $618(66)$ & 0.029 & $1.74(1.05-2.89)$ \\
\hline Subtype non-B $[n(\%)]^{g}$ & $335(33)$ & $21(23)$ & $314(34)$ & & \\
\hline
\end{tabular}

TDRM, patients infected with HIV-1 with TDRMs; wild type, patients infected with wild-type HIV-1; HPC, high-prevalence country, countries where the prevalence of HIV in the general population exceeds $1 \%$; CDC, Centers for Disease Control. Proportions were compared with $t$-test or Mann-Whitney $U$-test. $\mathrm{Cl}$, confidence interval, odds ratio $(\mathrm{OR})$ are calculated with $\chi^{2}$-test and logistic regression analysis.

${ }^{a}$ Description of patients from whom a baseline HIV genotypic analysis was available.

${ }^{\mathrm{b}}$ Data were available for 1047 patients.

${ }^{\mathrm{c}}$ Data were available for 1040 patients.

${ }^{\mathrm{d} D a t a}$ were available for 1050 patients.

eData were available for 937 patients.

'Data were available for 1013 patients.

${ }^{\mathrm{g}}$ Data were available for 1025 patients. 
CRF02_AG 4.3\%, G 4.2\% and less frequently ( $<2 \%) \mathrm{D}$, F, H, J, CRF03_AB, CRF06_cpx, CRF11_cpx and CRF13_cpx. Seventeen (1.6\%) sequences could not be classified. The overall prevalence of TDRMs in HIV-1 strains from newly diagnosed drug naive individuals in Europe was 9.1\% (96/1050, 95\% CI: 7.5-11.1).

Several factors that might affect the risk of becoming infected with drug-resistant virus were explored (Table 1). The prevalence of TDRM-HIV was not significantly higher in individuals infected for less than 1 year than in individuals with undefined duration of infection [10.6 vs. $8.7 \%$; odds ratio (OR) $=1.3$ (95\% CI: 0.7-2.0); $P=0.37$. TDRMs were identified more frequently in subtype $\mathrm{B}$ viruses $(10.4 \%)$ than in non-B viruses $(6.3 \%)[\mathrm{OR}=1.74$ (95\% CI: 1.05-2.89); $P=0.03$ ]. This difference could be attributed to the lower prevalence of TDRM-HIV in viruses from individuals originally from or known to be infected in countries with a high prevalence of HIV-1 compared with men having sex with men (MSM) [5.2 vs. 10.0\%; OR $=0.49$ (95\% CI: 0.24-0.99); $P=0.046]$. In fact, when we only considered patients who had been infected within Europe, the prevalence of TDRMs was more comparable among patients infected with subtype B or non-B virus $[10.6$ vs. $8.1 \%$; $\mathrm{OR}=1.3(0.7-2.7)$; $P=0.4]$.

Furthermore, we explored the relationship between the presence of TDRM-HIV and infection with other sexually transmitted diseases and sex with anonymous persons and sex for money. None of these factors was significant predictor of infection with drug-resistant HIV-1 using univariate analysis (data not shown). Furthermore, at the time of diagnosis, there were no relevant differences in Centers for Disease Control stages, HIV-RNA levels (4.8 and $4.9 \log$ copies/ml) or CD4 cell counts (370 and 328 cells $/ \mu \mathrm{l})$ between individuals infected with TDRMHIV or WT-HIV.

Interestingly, among the individuals infected with TDRM-HIV, revertants on position 215 in RT were more frequently detected in individuals with undefined duration of infection $[25 / 71(35.2 \%)]$ than in individuals infected for less than 1 year $(3 / 25,12.0 \%)[\mathrm{OR}=3.99$ (95\% CI: 1.09-14.64); $P=0.037]$. This result, however, should be confirmed in future studies, as the estimate of

Table 2. Susceptibility of HIV strains with single transmitted drug resistance mutations.

\begin{tabular}{|c|c|c|c|c|c|c|c|c|c|c|}
\hline \multirow[b]{2}{*}{ Mutation } & & \multicolumn{2}{|c|}{ Prevalence } & & & & & & & \\
\hline & & Total $n^{\mathrm{a}}$ & As single $(\%)^{b}$ & \multicolumn{7}{|c|}{ Predicted susceptibility to antiretroviral drugs } \\
\hline NRTI-related & & & & ZDV & D4T & $3 \mathrm{TC}$ & FTC & $A B C$ & DDI & TDF \\
\hline Any & - & 57 & $31(54)$ & - & - & - & - & - & - & - \\
\hline $41^{\mathrm{c}}$ & $\mathrm{L}$ & 12 & $2(17)$ & I & $\mathrm{S}$ & $\mathrm{S}$ & $\mathrm{S}$ & S & S & S \\
\hline 44 & D & 4 & $2(50)$ & S & S & $\mathrm{S}$ & S & $S$ & S & S \\
\hline 62 & V & 5 & $1(20)$ & $\mathrm{S}$ & $\mathrm{S}$ & $\mathrm{S}$ & $\mathrm{S}$ & $\mathrm{S}$ & $\mathrm{S}$ & $\mathrm{S}$ \\
\hline $70^{\mathrm{c}}$ & $\mathrm{R}$ & 6 & $1(17)$ & I & $\mathrm{S}$ & $\mathrm{S}$ & $\mathrm{S}$ & $\mathrm{S}$ & $\mathrm{S}$ & $\mathrm{S}$ \\
\hline 77 & $\mathrm{~L}$ & 4 & $2(50)$ & $S$ & $S$ & $S$ & $S$ & $S$ & $S$ & S \\
\hline 116 & $\mathrm{Y}$ & 3 & $1(33)$ & $\mathrm{S}$ & $\mathrm{S}$ & $\mathrm{S}$ & $\mathrm{S}$ & $\mathrm{S}$ & $\mathrm{S}$ & $\mathrm{S}$ \\
\hline 184 & V & 8 & $2(25)$ & $\mathrm{S}$ & $\mathrm{S}$ & $\mathrm{R}$ & $\mathrm{R}$ & $\mathrm{S}$ & $\mathrm{S}$ & $\mathrm{S}$ \\
\hline $215^{\mathrm{c}}$ & rev & 28 & $18(64)$ & I & $\mathrm{S}$ & $\mathrm{S}$ & $\mathrm{S}$ & $\mathrm{S}$ & $\mathrm{S}$ & $\mathrm{S}$ \\
\hline $219^{\mathrm{c}}$ & $\mathrm{Q}, \mathrm{E}$ & 10 & $2(20)$ & I & $S$ & $S$ & $S$ & S & $S$ & S \\
\hline NNRTI-related & & & & EFV & NVP & & & & & \\
\hline Any & - & 27 & $16(59)$ & - & - & & & & & \\
\hline 103 & $\mathrm{~N}$ & 11 & $4(36)$ & $\mathrm{R}$ & $\mathrm{R}$ & & & & & \\
\hline 108 & I & 8 & $7(88)$ & $\mathrm{S}$ & $\mathrm{S}$ & & & & & \\
\hline 181 & C & 3 & $1(33)$ & I & $\mathrm{R}$ & & & & & \\
\hline 188 & $\mathrm{H}$ & 1 & $1(100)$ & I & $\mathrm{R}$ & & & & & \\
\hline 190 & A & 4 & $2(50)$ & I & $\mathrm{R}$ & & & & & \\
\hline 230 & $\mathrm{~L}$ & 1 & $1(100)$ & $\mathrm{R}$ & $\mathrm{R}$ & & & & & \\
\hline Pl-related & & & & $\mathrm{APV} / \mathrm{r}$ & ATV/r & $\mathrm{IDV} / \mathrm{r}$ & $\mathrm{LPV} / \mathrm{r}$ & $\mathrm{SQV} / \mathrm{r}$ & $\mathrm{TPV} / \mathrm{r}$ & \\
\hline Any & - & 32 & $21(66)$ & - & - & - & - & - & - & \\
\hline 30 & $\mathrm{~N}$ & 4 & $4(100)$ & $\mathrm{S}$ & $\mathrm{S}$ & $\mathrm{S}$ & $\mathrm{S}$ & $\mathrm{S}$ & $\mathrm{S}$ & \\
\hline 46 & $\mathrm{I}, \mathrm{L}$ & 15 & $7(47)$ & $\mathrm{S}$ & $\mathrm{S}$ & $\mathrm{S}$ & $\mathrm{S}$ & $\mathrm{S}$ & $\mathrm{S}$ & \\
\hline 82 & $A, F$ & 8 & $3(38)$ & S & S & S & S & S & S & \\
\hline 90 & M & 13 & $7(54)$ & S & S & S & $\mathrm{S}$ & $S$ & S & \\
\hline
\end{tabular}

Susceptibility was predicted using the Rega resistance interpretation algorithm (V6.4.1) [13]. NNRTI, non-nucleoside reverse transcriptase inhibitor; NRTI, nucleoside reverse transcriptase inhibitor; PI, protease inhibitor; rev, revertant: one of the following mutations at position 215 in reverse transcriptase: A/C/D/E/G/H/I/L/N/S/V; ZDV, zidovudine; D4T, stavudine; 3TC, lamivudine; FTC, emtricitabine; ABC, abacavir; DDI, didanosine; TDF, tenofovir; EFV, efavirenz; NVP, nevirapine; APV, amprenavir; ATV, atazanavir; IDV, indinavir; LPV, lopinavir; SQV, saquinavir; TPV, tipranavir; r, ritonavir.

aPresence of transmitted drug resistance mutations (TDRMs) at a specific codon.

${ }^{\mathrm{b}}$ Number and proportion of TDRMs per codon that occurs as single TDRMs in a sequence.

${ }^{\mathrm{C}} \mathrm{TAMS}$, thymidine analogue associated mutations. 
the OR was rather imprecise as indicated by the wide limits of the $95 \%$ CI. Similarly, mixtures at resistancerelated positions were more frequent in individuals with undefined duration of infection $[20 / 71(28.2 \%)$ vs. $5 / 25$ $(20 \%)][\mathrm{OR}=1.57$ (95\% CI: 0.52-4.75); $P=0.43]$, but this difference was not statistically significant.

Mutations associated with resistance to nucleoside reverse transcriptase inhibitors (NRTIs) were observed most frequently $[57 / 1050(5.4 \%)]$, followed by mutations related to protease inhibitors (PIs) [32/1050 (3.0\%)] and mutations related to non-nucleoside reverse transcriptase inhibitors (NNRTIs) [27/1050 (2.6\%)]. The majority [68/96 (71\%)] of strains with TDRMs harboured only single drug resistance related amino acid substitutions (Table 2). Consequently, among individuals carrying HIV-1 strains with resistance mutations, a limited proportion [14/96 (14.6\%)] harboured mutations related to more than one class of drugs (Table 3 ).

To evaluate the potential impact of baseline resistance on the efficacy of future therapy, we analysed the RT and protease genotypes using three resistance interpretation algorithms The great majority [967/1050 (92.1\%)] of the $1050 \mathrm{HIV}-1$ strains identified from the newly diagnosed individuals was fully susceptible to all drugs in the three classes. Within the group of viruses with TDRMs, $79.2 \%$ of the strains displayed full susceptibility to all NNRTIs, $82.3 \%$ to all PIs and $44.8 \%$ to all NRTIs (Fig. 1). Moreover, 25\% (24/96) of the TDRM-HIV strains were predicted to be fully susceptible to all drugs. These 25 strains contained only single amino acid substitutions, with limited impact on resistance, and therefore were predicted not to have an impact on therapy outcome.

Reduced susceptibility in the remaining TDRMcontaining strains was frequently limited to one or only a few drugs within a class (Tables 2 and 3). Some exceptions, however, existed where resistance was quite extensive and affected all drugs of a class (Table 2 NNRTI section, and Table 3). Twenty strains [20/96 (20.8\%)] had reduced NNRTI class susceptibility, 14 of these strains were predicted to display high level of resistance to both currently approved NNRTIs. Four strains $(4.2 \%)$ had reduced susceptibility to all drugs of the NRTI class, one of them was predicted to have high-level resistance to each NRTI. Three (3.1\%) strains had reduced susceptibility to all PIs but none was predicted to be highly resistant to all PIs.

Table 3. Characteristics and susceptibility of HIV strains with multiple transmitted drug resistance mutations.

\begin{tabular}{|c|c|c|c|c|c|c|c|}
\hline \multirow[b]{2}{*}{$N$} & \multirow[b]{2}{*}{ NRTI mutations } & \multirow[b]{2}{*}{ NNRTI mutations } & \multirow[b]{2}{*}{ PI mutations } & \multicolumn{4}{|c|}{ Number of fully active drugs ${ }^{a}$} \\
\hline & & & & $<1$ year & NRTIs (7) & NNRTIs (2) & bPls (6) \\
\hline $1^{\mathrm{b}}$ & $41 \mathrm{~L}, 44 \mathrm{D}, 67 \mathrm{~N}, 74 \mathrm{~V}, 184 \mathrm{~V}, 210 \mathrm{~W}, 215 \mathrm{Y}$ & $190 \mathrm{~S}$ & $48 \mathrm{~V}, 82 \mathrm{~S}, 90 \mathrm{M}$ & Yes & 0 & 0 & 0 \\
\hline 2 & $41 \mathrm{~L}, 44 \mathrm{D}, 74 \mathrm{VL}, 215 \mathrm{NHY}$ & $103 \mathrm{NK}, 181 \mathrm{C}, 190 \mathrm{~A}$ & $46 \mathrm{~L}, 82 \mathrm{~A}$ & & 3 & 0 & 0 \\
\hline $3^{\mathrm{b}}$ & $41 \mathrm{~L}, 62 \mathrm{~V}, 75 \mathrm{I}, 215 \mathrm{~F}$ & $100 \mathrm{I}, 103 \mathrm{~N}$ & $46 \mathrm{I}, 84 \mathrm{~V}, 90 \mathrm{M}$ & Yes & 6 & 0 & 0 \\
\hline 4 & $41 \mathrm{~L}, 62 \mathrm{~V}, 215 \mathrm{Y}$ & 181C, 190A & $46 \mathrm{I}, 84 \mathrm{~V}, 90 \mathrm{M}$ & & 2 & 0 & 2 \\
\hline 5 & $41 \mathrm{~L}, 215 \mathrm{D}$ & - & - & & 6 & 2 & 6 \\
\hline 6 & $41 \mathrm{~L}, 215 \mathrm{D}$ & - & - & & 6 & 2 & 6 \\
\hline 7 & $41 \mathrm{~L}, 215 \mathrm{D}$ & - & - & & 6 & 2 & 6 \\
\hline $8^{\mathrm{b}}$ & $41 \mathrm{~L}, 210 \mathrm{~W}, 215 \mathrm{D}$ & - & - & Yes & 5 & 2 & 6 \\
\hline 9 & $41 \mathrm{~L}, 210 \mathrm{~W}, 215 \mathrm{D}$ & - & - & & 5 & 2 & 6 \\
\hline 10 & $41 \mathrm{~L}, 215 \mathrm{~N}$ & & $90 \mathrm{M}$ & & 6 & 2 & 6 \\
\hline 11 & $62 \mathrm{~V}, 70 \mathrm{RK}, 75 \mathrm{I}, 77 \mathrm{~L}, 116 \mathrm{Y}, 151 \mathrm{M}$ & $103 \mathrm{~N}, 108 \mathrm{I}$ & $46 \mathrm{I}, 50 \mathrm{~V}, 82 \mathrm{~A}$ & & 0 & 0 & 1 \\
\hline 12 & $62 \mathrm{~V}, 75 \mathrm{I}, 77 \mathrm{~L}, 115 \mathrm{~F}, 116 \mathrm{Y}, 151 \mathrm{M}$ & $103 \mathrm{~N}$ & $46 \mathrm{I}, 50 \mathrm{~V}, 82 \mathrm{~A}$ & & 0 & 0 & 1 \\
\hline 13 & $65 \mathrm{RK}, 151 \mathrm{M}$ & 181C & - & & 0 & 0 & 6 \\
\hline 14 & $67 \mathrm{~N}, 219 \mathrm{E}$ & - & - & & 6 & 2 & 6 \\
\hline 15 & $67 N, 219 Q$ & - & - & & 6 & 2 & 6 \\
\hline 16 & $67 N, 219 Q$ & - & - & & 6 & 2 & 6 \\
\hline 17 & $67 \mathrm{~N}, 69 \mathrm{D}, 70 \mathrm{R}, 184 \mathrm{~V}, 219 \mathrm{Q}$ & - & $46 \mathrm{~L}, 82 \mathrm{~A}$ & & 1 & 2 & 1 \\
\hline 18 & $67 \mathrm{~N}, 69 \mathrm{D}, 70 \mathrm{R}, 215 \mathrm{~F}, 219 \mathrm{Q}$ & - & - & & 3 & 2 & 6 \\
\hline 19 & $67 \mathrm{~N}, 70 \mathrm{R}, 184 \mathrm{~V}, 219 \mathrm{Q}$ & - & - & & 1 & 2 & 6 \\
\hline 20 & $67 \mathrm{~N}, 70 \mathrm{R}, 219 \mathrm{Q}$ & - & - & & 4 & 2 & 6 \\
\hline $21^{\mathrm{b}}$ & $184 \mathrm{~V}$ & $103 \mathrm{~N}$ & - & Yes & 5 & 0 & 6 \\
\hline 22 & $184 \mathrm{~V}$ & 181C & - & & 5 & 0 & 6 \\
\hline $23^{\mathrm{b}}$ & $184 \mathrm{~V}, 215 \mathrm{~F}$ & - & $46 \mathrm{I}, 90 \mathrm{M}$ & Yes & 4 & 2 & 3 \\
\hline 24 & $215 \mathrm{~L}$ & - & $46 \mathrm{~L}$ & & 6 & 2 & 6 \\
\hline 25 & $215 S$ & - & $90 \mathrm{M}$ & & 6 & 2 & 6 \\
\hline 26 & 215S, 219Q & - & - & & 6 & 2 & 6 \\
\hline 27 & - & $103 \mathrm{~N}, 225 \mathrm{H}$ & - & & 7 & 0 & 6 \\
\hline 28 & - & $103 \mathrm{~N}, 225 \mathrm{P} / \mathrm{H}$ & - & & 7 & 0 & 6 \\
\hline
\end{tabular}

Susceptibility was predicted using the Rega resistance interpretation algorithm (V6.4.1) [13].

${ }^{a}$ Resistance-related polymorphisms (not listed) are included in the estimation of drug activity. Nucleoside reverse transcriptase inhibitors (NRTIs): abacavir, didanosine, emtricitabine, lamivudine, stavudine, tenofovir and zidovudine. Non-nucleoside reverse transcriptase inhibitors (NNRTIs): efavirenz and nevirapine. bPIs, boosted protease inhibitors (PIs): atazanavir/r, fosamprenavir/r, indinavir, lopinavir/r, saquinavir/r and tipranavir/r.

${ }^{\mathrm{b}}$ These strains were identified in individuals with documented recent infection $(<1$ year). 
Reduced susceptibility to NRTIs

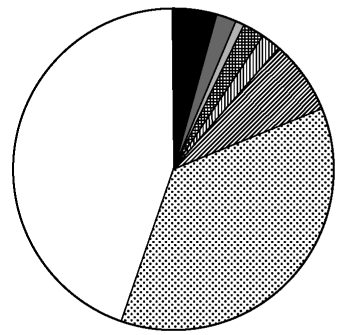

Reduced susceptibility to NNRTIs

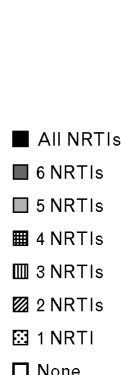

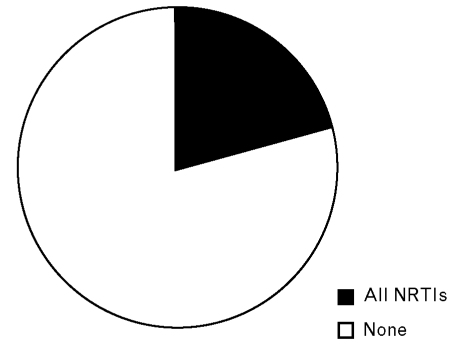

Reduced susceptibility to boosted PIs

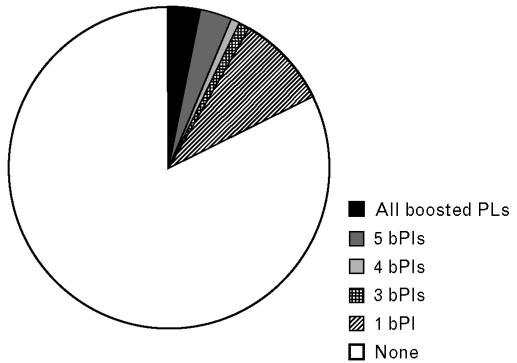

Fig. 1. Estimated susceptibility to antiretroviral drugs of viruses with transmitted drug resistance mutations (TDRMs). Reduced susceptibility of the 96 viruses with TDRMs to the different drug classes was calculated using the Rega algorithm. Nucleoside reverse transcriptase inhibitors (NRTIs): abacavir, didanosine, emtricitabine, lamivudine, stavudine, tenofovir and zudividine. Non-nucleoside reverse transcriptase inhibitors (NNRTIs): efavirenz and nevirapine. Boosted protease inhibitors (PIs): amprenavir/ $r$, atazanavir/r, idinavir/r, lopinavir/r, saquinavir/r and tipranavir/r.

Remarkably, in one individual, the resistance pattern was so extensive that none of the currently available antiretroviral drugs was predicted to be fully active. Loss of susceptibility was most extensive for the NRTI zidovudine, with only $50 \%(48 / 96)$ of the strains with TDRMs predicted to be fully susceptible, $27.1 \%$ displaying intermediate resistance and $22.9 \%$ high-level resistance. In contrast, the least affected drug was the PI tipranavir, for which $96.9 \%$ of all strains harbouring TDRMs were predicted to be fully susceptible.

\section{Discussion}

The SPREAD programme is the first large, prospective and sufficiently powered multinational European study performing a well-controlled assessment of the prevalence of transmitted drug resistance. This study prospectively studied transmission of resistant virus in a representative population of over 1000 newly diagnosed HIV-1-infected individuals, consisting of 235 individuals in whom a recent seroconversion was documented.

Our study shows that the prevalence of viruses with transmitted drug resistance mutations in newly diagnosed individuals is around $9 \%$ and that in the majority of individuals only single drug resistance-related mutations are detected.

For two reasons, it cannot be excluded that we underestimate the transmission of drug-resistant mutations. First, we used population sequencing for detection of resistance-related mutations and it is possible that mutant populations comprising a minority of the viral population remained undetected $[15,16]$. Second, we assessed prevalence of TDRMs among newly HIV-1diagnosed individuals. The population of newly diagnosed individuals in our study represents a range from acutely infected individuals to those with a chronic HIV-1 infection. Although persistence of drug-resistant mutant viruses in the absence of selection pressure of therapy frequently has been reported [17-20], it is possible that in the period between infection and diagnosis, reversion to wild-type and/or outgrowth of minority wild-type species may result in disappearance of resistant viruses from plasma. Indeed, we observed a trend towards a higher prevalence of resistance-related mutants but a lower prevalence of mixture and revertants in individuals with documented recent infection. These results indicate that transmitted mutations can revert over time in the absence of therapy.

In the retrospective Child and Adolescent Trial for Cardiovascular Health (CATCH) study, which collected samples from 1996 to 2002 before the start of the prospective SPREAD programme, we reported earlier a higher prevalence of TDRMs in subtype B viruses than in non-B viruses [21]. Also, in this prospective study, we identified more frequently TDRMs in subtype B viruses compared with non-B viruses (10.4 vs. 6.3\%). Using the epidemiological data collected in the SPREAD programme, we established that a vast majority of patients from or known to be infected in countries with a high prevalence of HIV-1 carried predominantly non-B virus, the wild-type HIV-1. In contrast, the prevalence of TDRM-HIV was equally distributed among B and nonB strains carried by patients who had been infected in Europe. This indicates that the overall difference observed is not attributed to specific viral characteristics of non-B strains but rather to the lack of exposure to drugs in the high-prevalence countries [22].

With the current lack of prospective data collected over a prolonged period, making definite statements regarding the patterns and prevalence of TDRM changes over time is still difficult. In the retrospective CATCH study, however, a prevalence of TDRMs of $10 \%$ was reported from surveillance data from several European countries between 1996 and 2002 [21]. In Fig. 2, the incidence of 


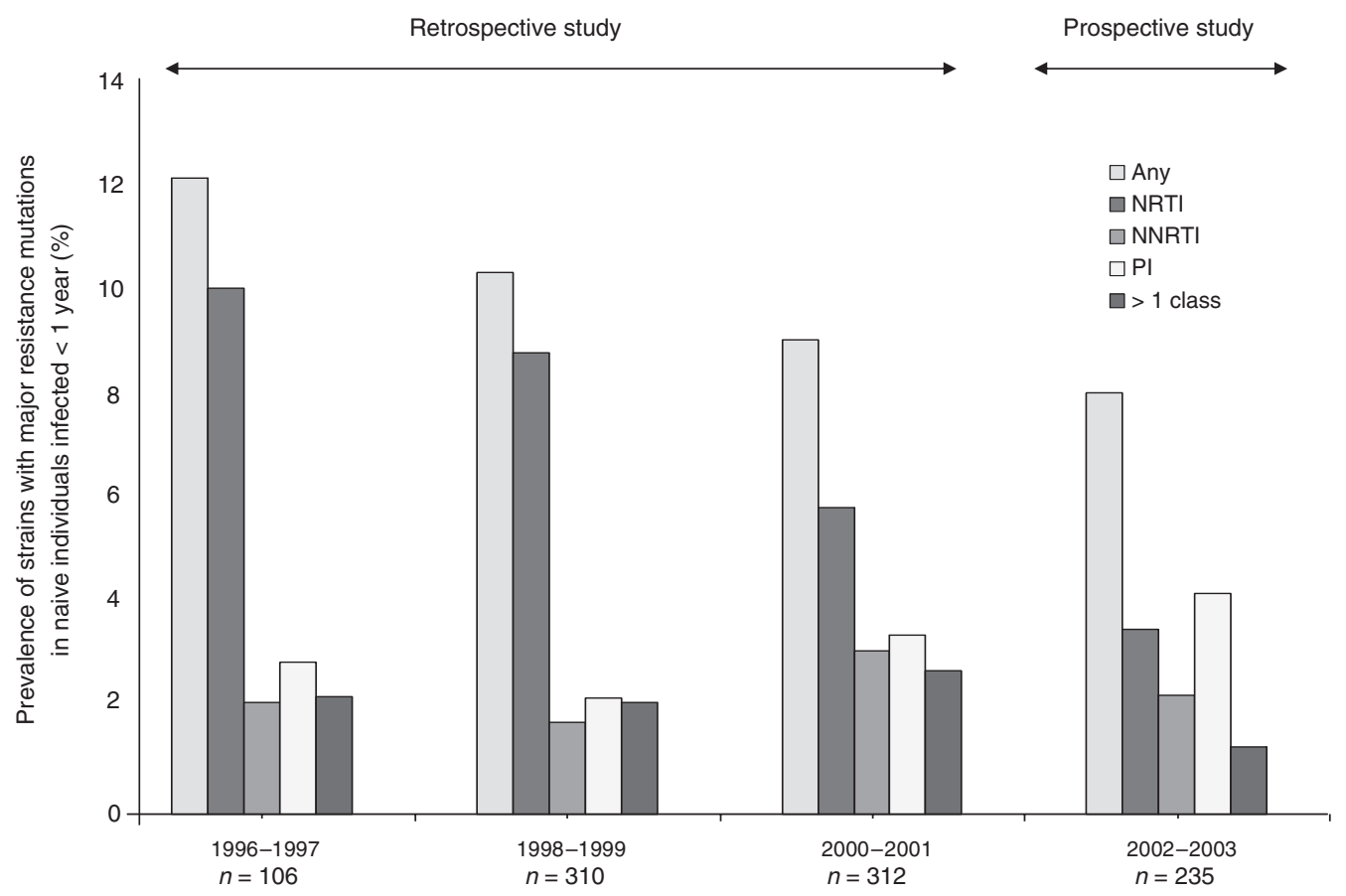

Fig. 2. Transmitted drug resistance over time. NNRTI, non-nucleoside reverse transcriptase inhibitor; NRTI, nucleoside reverse transcriptase inhibitor; PI, protease inhibitor.

TDRMs in recently infected patients $(<1$ year) from the retrospective CATCH study (data taken from 1996 to 2001) and the prospective SPREAD study (data from 2002 to 2003) is shown. Despite the limitations of comparing two datasets with different sampling strategies, it is still of interest to see that the proportion of recently infected individuals diagnosed with strains harbouring TDRMs does not continue to rise but seems to decrease over time in Europe [23] (Fig. 2).

The results of SPREAD are generally consistent with the results of several other studies that recruited various risk groups from individual high-income countries, with prevalences ranging from 0 to $17 \%$ in Europe [4]. Some observational and retrospective studies in the US and UK observed an increased prevalence of TDRMs in recently infected individuals over time to more than $20 \%$ in recent years [24-27]. These studies, however, had a different design with an inclusion of predominantly MSM in urban areas exposed to highly antiretroviral drugs. In contrast, a sentinel study describing data from 1083 individuals collected during 1998-2000 in several cities in the US using a consecutive sampling approach observed a prevalence of TDRMs of $7.4 \%$ among chronically infected patients and $12 \%$ among recently infected patients [5]. The prevalence of TDRMs in this study was significantly higher in MSM (11\% in chronically and 15\% in recently infected) than in heterosexual infected individuals. In our study, the prevalence of TDRMs was comparable and not significantly higher in MSM as compared with heterosexual individuals infected in Europe (11 vs. 10\%). The prevalence of TDRMs in MSM, however, was signifi- cantly higher compared with patients coming from outside Europe (5.5\%). These results indicate the importance of collection of epidemiological data from all transmission groups for surveillance of TDRMs.

Insights into the dynamics of transmission of drugresistant viruses can be obtained by analysing the patterns of transmitted mutations in more detail. The predominance of single thymidine-associated mutations (TAMSs) and 215 revertants can be explained by a combination of factors. TAMSs are selected by the thymidine analogues (zidovudine and stavudine); therefore, transmission of viruses with solitary TAMS most likely reflects a predominant circulation of these viruses at points in time (e.g. late 1980s and early 1990s), when there was extensive use of non-suppressive mono and dual therapies with thymidine analogues. Introduction of highly active antiretroviral therapy in the mid-1990s caused a more equal distribution of resistance among the three classes in patients with treatment failure. As a result, more recent transmissions patterns show a relative decrease in the proportion of NRTI resistance (Fig. 2).

Given the fact that the majority of the HIV-1 strains harboured only a single mutation, the effect on the response to future therapy may be limited. Indeed, a quarter of the isolated viruses harbouring TDRMs were predicted to be fully susceptible to all currently approved antiretroviral drugs. Nevertheless, identification of these resistance-related mutations is essential as they give insight into the transmission patterns of viruses that have been exposed to therapy in previous hosts. 
The predicted effect of other single TDRMs on therapy outcome depends on the specific class of antiretroviral drugs. The presence of most single TAMS is not predicted to affect initial therapy response dramatically, especially given that NRTIs are in general combined with a NNRTI or PI. Then again, the presence of baseline resistance mutations can decrease the genetic barrier, reducing the number of mutations necessary for loss of susceptibility. For instance, the presence of baseline 215 revertants has been reported to be associated with a higher risk of virological failure on regimens containing a thymidine analogue [28].

The effect of single PI mutations on first-line therapy is expected to be limited in the era of boosted PIs because multiple mutations have to be generated before therapy fails [29].

In contrast, most solitary NNRTI mutations are sufficient for a complete loss of activity of the first-generation NNRTIs (efavirenz and nevirapine) [30]. Treatment guidelines advise to initiate first-line therapy with a boosted PI or a NNRTI accompanied by a NRTI backbone. As solitary mutations may dramatically effect the susceptibility of NNRTIs, we support the recommendations for baseline resistance testing for newly diagnosed individuals and, if necessary, subsequent customizing of initial therapy. Furthermore, minority strains with transmitted drug resistance related mutations might not always be detected by conventional resistance testing $[15,16]$. A single mutation or a revertant might be an indication that more extensive resistance has been transmitted. Therefore, in cases of infection with HIV-1 carrying a single transmitted drug resistance mutation, the initiation of antiretroviral combination regimens with a high genetic barrier should be considered. In addition, treatment response should be closely monitored and resistance testing should be urgently considered if treatment failure is suspected.

In conclusion, we have shown that the prevalence of viruses with transmitted drug resistance mutations in newly diagnosed individuals in Western Europe and Israel is approximately $9 \%$ and that in the majority of cases detection is limited to single drug resistance-related mutations.

Continuous monitoring remains indicated to determine the patterns, rates and factors contributing to the transmission of TDRMs, as well as the potential clinical consequences.

\section{Acknowledgements}

This study was funded by grants from European Commission: QLK2-CT-2001-01344, 5th Framework. Belgium: The Belgian AIDS Reference Laboratory fund, the Belgian Fonds voor Wetenschappelijk Onderzoek (F.W.O. G.0266.04). Denmark: The Danish AIDS foundation. Germany: Federal Ministry of Health (grant 325-4476-02/3) and the Federal Ministry of Education and Research (grant 01 KI 0211). Italy: 5th National Programme on HIV/AIDS, Istituto Superiore di Sanità (grants N 40F.56 and 20D.1.6). Luxembourg: The Fondation Recherche sur le SiDA and the Ministry of Health. Serbia Montenegro: Ministry of Science and Environmental of the Republic of Serbia Montenegro (grant 145047). Sweden: Swedish Research Council. Spain: Maraton TV3 Foundation (MARATÓN-TV3/02-1730).

Writing committee: Annemarie M.J. Wensing, University Medical Center, Utrecht, the Netherlands, Jurgen Vercauteren, Katholieke Universiteit Leuven, Leuven, Belgium; David A. van de Vijver, University Medical Center, Utrecht, the Netherlands; Jan Albert, Swedish Institute for Infectious Disease Control, Solna, Sweden; Birgitta Åsjö, University of Bergen, Bergen, Norway; Claudia Balotta, University of Milan, Milan, Italy; Ricardo Camacho, Hospital Egas Moniz, Lisbon, Portugal; Suzie Coughlan, National Virus Reference Laboratory, University College Dublin, Dublin, Ireland; Zehava Grossman, Sheba Medical Center, Tel-Hashomer, Israel; Andrzej Horban, Hospital for Infectious Diseases \& AIDS Diagnosis and Therapy Center, Warsaw, Poland; Claudia Kücherer, Robert Koch Institute, Berlin, Germany; Claus Nielsen, Statens Serum Institute, Copenhagen, Denmark; Dimitris Paraskevis, Athens University Medical School, Athens, Greece; Wei C. Loke, Guys and St Thomas' Hospital, London, UK; Gabrielle Poggensee, Robert Koch Institute, Berlin, Germany; Elisabeth Puchhammer-Stöckl, University of Vienna, Vienna, Austria; Chiara Riva, University of Milan, Milan, Italy; Lidia Ruiz, Retrovirology Laboratory IRSICAIXA Foundation, Badalona, Spain; Jean-Claude Schmit, Centre Hospitalier de Luxembourg, Luxembourg; Rob Schuurman, University Medical Center, Utrecht, the Netherlands; Mika Salminen, National Public Health Institute, Helsinki, Finland; Anders Sonnerborg, Karolinska University Hospital, Stockholm, Sweden; Maja Stanojevic, University of Belgrade School of Medicine and Ministry of Health, Serbia Montenegro; Daniel Struck, Centre Hospitalier de Luxembourg, Luxembourg; AnneMieke Vandamme, Katholieke Universiteit Leuven, Leuven, Belgium; Charles A.B. Boucher, University Medical Center, Utrecht, the Netherlands, on behalf of the SPREAD programme.

SPREAD national coordinators: E. Puchhammer-Stockl, Austria; A.-M. Vandamme, Belgium; C. Nielsen, Denmark; M. Salminen, Finland; K. Korn, Germany; A. Hatzakis, Greece; W. Hall, Ireland; Z. Grossman, Israel; C. Balotta, Italy; J. Albert, Sweden; J.C. Schmit, Luxembourg; C.A.B. Boucher and A.M.J. Wensing, the Netherlands; B. Asjö, Norway; A. Horban, Poland; R. Camacho, Portugal; M. Stanejovic, Serbia Montenegro; B. Clotet, Spain; D. Pillay, UK. 
Programme coordination team: C.A.B. Boucher, A.M.J. Wensing, R. Schuurman, D.A.M.C. van de Vijver, A.I. Stolwijk, M. Toet.

Data analysis team: J. Albert, C. Balotta, G. Poggensee, C. Kucherer, J.-C. Schmit, D. Struck, A.-M. Vandamme, J. Vercauteren, D.A. van de Vijver, A.M.J. Wensing.

SPREAD investigators:

Austria: M. Sarcletti, B. Schmied, M. Geit, G. Balluch.

Rega Institute for Medical Research and University Hospitals, Leuven, Belgium: J. Vercauteren, K. Van Laethem, A. Abecasis, I. Derdelinckx, K. Deforche; Universitair Ziekenhuis Gent, Gent, Belgium: M. Bogaert; Rega Institute for Medical Research and University Hospitals, Leuven, Belgium: H. Ceunen; St Pierre University Hospital, Brussels, Belgium: S. De Wit; Academisch Ziekenhuis, Vrije Universiteit Brussel, Brussel, Belgium: F. Echahidi; Cliniques Universitaires de Bruxelles, Hôpital Erasme, Brussels, Belgium: C.M. Farber; Prince Leopold Institute of Tropical Medicine, Antwerpen, Belgium: K. Fransen; Cliniques Universitaires de Bruxelles, Hôpital Erasme, Brussels, Belgium: J.C. Goffard; St Pierre University Hospital, Brussels, Belgium: E. Goudeseune; Cliniques Universitaires StLuc, Brussels, Belgium: A. Henry; Academisch Ziekenhuis, Vrije Universiteit Brussel, Brussel: P. Lacor; Cliniques Universitaires de Bruxelles, Hôpital Erasme, Brussels, Belgium: C. Liesnard; University of Liège, Liège, Belgium: M. Moutschen; Academisch Ziekenhuis, Vrije Universiteit Brussel, Brussel: D. Pierard; Rega Institute for Medical Research and University Hospitals, Leuven, Belgium: R. Rens, Y. Schrooten; University of Liège, Liège, Belgium: D. Vaira; Cliniques Universitaires St-Luc, Brussels, Belgium: B. Vandercam; Prince Leopold Institute of Tropical Medicine, Antwerpen, Belgium: A. Van den Heuvel; Universitair Ziekenhuis Gent, Gent, Belgium: B. Van Der Gucht; Rega Institute for Medical Research and University Hospitals, Leuven, Belgium: M. Van Ranst, E. Van Wijngaerden; Universitair Ziekenhuis Gent, Gent, Belgium: C. Verhofstede; St Pierre University Hospital, Brussels, Belgium: N. Clumeck; Scientific Institute of Public Health, Brussels, Belgium: A. Sasse; Rega Institute for Medical Research and University Hospitals, Leuven, Belgium: A.-M. Vandamme.

Denmark: L.B. Jørgensen, J. Gerstoft, L. Mathiesen, C. Pedersen, H. Nielsen, A. Laursen, B. Kvinesdal.

Finland: M. Ristola, K. Liitsola, J. Suni, J. Sutinen.

Labor Berg, Berlin, Germany: T. Berg; PZB, Aachen, Germany: P. Braun; Robert Koch Institute, Berlin, Germany: G. Breugelmans; University of Cologne,
Cologne, Germany: M. Däumer; Max von Pettenkofer Institut, München, Germany: J. Eberle; Robert Koch Institute, Berlin, Germany: O. Hamouda; Hannover Medical School, Hannover, Germany: H. Heiken; University of Cologne, Cologne, Germany: R. Kaiser; PZB, Aachen, Germany: H. Knechten; Fenner and Partner, Hamburg, Germany: H. Müller; Labor Berg, Berlin, Germany: S. Neifer; University of ErlangenNuremberg, Germany: B. Schmidt, H. Walter.

Athens University Medical School, Athens, Greece: A. Hatzakis, D. Paraskevis, E. Magiorkinis, E. Hatzitheodorou.

National Virus Reference Laboratory, University College Dublin, Ireland: C. Byrne, M. Duffy; St. James's Hospital, Dublin, Ireland: C. Bergin, G. Farrell, A. Rochford, J. Low, P. Coakely; National Virus Reference Laboratory, University College Dublin, Ireland: W. Hall.

Israel: I. Levi, D. Chemtob.

University of Milan, Milan, Italy: C. Riva; University of Modena, Modena, Italy: C. Mussini; University of Milan, Milan, Italy: I. Caramma, J. Cibella, A. Cappelletti; L. Sacco Hospital, Milan, Italy: A. Capetti; Sant'Anna Hospital of Como, Como, Italy: M.C. Colombo; San Camillo Hospital of Treviso, Treviso, Italy: C. Rossi; University of Modena, Modena, Italy: F. Prati; University of Palermo, Palermo, Italy: F. Tramuto, F. Vitale; Istituto Superiore di Sanità, Rome, Italy: M. Ciccozzi; University of Foggia, Foggia, Italy: G. Angarano; Istituto Superiore di Sanità, Rome, Italy: G. Rezza; University of Milan, Milan, Italy: C. Balotta.

Luxembourg: R. Hemmer, V. Arendt, T. Staub, F. Schneider, F. Roman.

Universitair Medisch Centrum Utrecht, Utrecht, the Netherlands: A.M.J. Wensing, D.A.M.C. van de Vijver; Ziekenhuis Rijnstate, Arnhem, the Netherlands: P.H.M. van Bentum; Onze Lieve Vrouwe Gasthuis, Amsterdam, the Netherlands: K. Brinkman; Rijksinstituut voor Volksgezondheid \& Milieu, Bilthoven, the Netherlands: E.L. op de Coul; Erasmus Medisch Centrum, Rotterdam, the Netherlands: M.E. van der Ende; Universitair Medisch Centrum Utrecht, Utrecht, the Netherlands: I.M. Hoepelman; St. Elisabeth Ziekenhuis, Tilburg, the Netherlands: M. van Kasteren, J. Juttmann, M. Kuipers; Ziekenhuis Rijnstate, Arnhem, the Netherlands: N. Langebeek; St. Elisabeth Ziekenhuis, Tilburg, the Netherlands: C. Richter, R.M.W.J. Santegoets, L. Schrijnders-Gudde; Universitair Medisch Centrum Utrecht, Utrecht, the Netherlands: R. Schuurman; St. Elisabeth Ziekenhuis, Tilburg, the Netherlands: B.J.M. van de Ven; Universitair Medisch Centrum Utrecht, Utrecht, the Netherlands: Charles A.B. Boucher. 
Department of Infectious Disease, Ullevaal University Hospital, Oslo, Norway: V. Ormaasen; The Norwegian Institute of Public Health, Oslo, Norway: P. Aavitsland, C. Holm-Hansen.

Hospital for Infectious Diseases \& AIDS Diagnosis and Therapy Center, Warsaw, Poland: J.J. Stanczak, G.P. Stanczak, E. Firlag-Burkacka; Medical University, Bialystok, Poland: A. Wiercinska-Drapalo; Medical University, Lodz, Poland: E. Jablonowska, E. Małolepsza; Pomeranian Medical University, Szczecin, Poland: M. Leszczyszyn-Pynka; National Institute of Hygiene, Warsaw, Poland: W. Szata.

Portugal: C. Palma, F. Borges, T. Paixão, V. Duque, F. Araújo, on behalf of the Portuguese SPREAD Network.

Serbia Montenegro: Dj. Jevtovic, D. Salemovic.

IrsiCaixa Foundation, Badalona, Spain: J. MartinezPicado; Hospital Ramon y Cajal, Madrid, Spain: C. Gutiérrez; C. de Mendoza; IrsiCaixa Foundation, Badalona, Spain: I. Erkicia; Hospital de la Santa Creu i Sant Pau, Barcelona, Spain: P. Domingo; Hospital Nuestra Donostia, San Sebastián, Spain: X. Camino; Hospital Clínico Universitario, Valencia, Spain: M.J. Galindo; Hospital Clínico, Barcelona, Spain: J.L. Blanco; Hospital Virgen del Rocío, Sevilla, Spain: M. Leal; Hospital de Palamós, Barcelona, Spain: A. Masabeu; Hospital del Mar, Barcelona, Spain: A. Guelar; Hospital Sant Jaume, Barcelona, Spain: J.M. Llibre; Hospital de la Santa Creu i Sant Pau, Barcelona, Spain: N. Margall; Hospital Nuestra Donostia, San Sebastián, Spain: J.A. Iribarren; Hospital Virgen del Rocío, Sevilla, Spain: S. Gutierrez; Hospital Clínico Universitario, Valencia, Spain: J.F. Baldoví; Hospital Juan Canalejo, A. Coruña, Spain: J.D. Pedreira; Hospital Clínico, Barcelona, Spain: J.M. Gatell; Hospital Ramon y Cajal, Madrid, Spain: S. Moreno; Hospital Carlos III, Madrid, Spain: B. Clotet; Hospital Ramon y Cajal, Madrid, Spain: V. Soriano; IrsiCaixa Foundation, Badalona, Spain: L. Ruiz on behalf of the Maraton TV3 Study Group.

Sweden: M. Arneborn, M. Gisslén, P. Björkman, G. Bratt, Annette Alaeus.

UK: D. Pillay, V. Delpech, D. Dunn.

J. Albert has given presentations for Abbott, Roche, BMS. B. Åsjö has given presentations for Abbott, Glaxo Smith Kline and Roche and received travel grants from Glaxo Smith Klein. C.A.B. Boucher has received travel and study grants and or participated in advisory boards for the following companies: Abbott, Boehringer Ingelheim, Bristol Myers Squibb, Bayer diagnostics, Glaxo Smith Kline, Roche, UCB-Pharma. R. Camacho has received travel grants and or participated in advisory boards for the following companies: Abbott, Boehringer Ingelheim, Bristol Myers Squibb, Glaxo Smith Kline. M. Salminen has given presentations for the following companies: Abbott, Roche J.C. Schmit has received travel and study grants or participated in advisory boards from the following companies: Abbott, Boehringer Ingelheim, Bristol Myers Squipp, Glaxo Smith Kline, Roche, UCBPharma. A. Sonnerborg has received study grants and/or participated in advisory boards for the following companies: Abbott, Jansen-Cilag, Glaxo Smith Kline, Medivir, Roche. A.M. Vandamme has received travel grants from Abbott, Bayer, Boehringer Ingelheim, Bristol Myers Squibb, Gilead, Glaxo Smith Kline, Merck, Roche and has participated in advisory boards of Abbott, Bayer, Boehringer Ingelheim and Gilead. A.M.J. Wensing has received travel grants, given presentations or participated in advisory boards for the following companies: Abbott, Boehringer Ingelheim Bristol Myers Squibb, Glaxo Smith Kline, Roche, Schering Plough.

\section{References}

1. Quinn TC, Wawer MJ, Sewankambo N, Serwadda D, Li C, Wabwire-Mangen $\mathrm{F}$, et al. Viral load and heterosexual transmission of human immunodeficiency virus type 1. Rakai Project Study Group [see comments]. N Engl J Med 2000; 342:921929; [see comments].

2. Leigh Brown AJ, Frost SD, Mathews WC, Dawson K, Hellmann NS, Daar ES, et al. Transmission fitness of drug-resistant human immunodeficiency virus and the prevalence of resistance in the antiretroviral-treated population. J Infect Dis 2003; 187:683686.

3. Kozal MJ, Amico KR, Chiarella J, Schreibman T, Cornman D, Fisher W, et al. Antiretroviral resistance and high-risk transmission behavior among HIV-positive patients in clinical care. AIDS 2004; 18:2185-2189.

4. Descamps D, Chaix ML, Andre P, Brodard V, Cottalorda J, Deveau $C$, et al. French national sentinel survey of antiretroviral drug resistance in patients with HIV-1 primary infection and in antiretroviral-naive chronically infected patients in 2001-2002. I Acquir Immune Defic Syndr 2005; 38:545-552.

5. Weinstock HS, Zaidi I, Heneine W, Bennett D, Garcia-Lerma JG, Douglas JM Jr, et al. The epidemiology of antiretroviral drug resistance among drug-naive HIV-1-infected persons in 10 US cities. I Infect Dis 2004; 189:2174-2180.

6. EuroHIV. HIV/AIDS Surveillance in Europe. End-year report 2005 No. 71; 2006. www.eurohiv.org.

7. Armitage P, Berry G, Matthews JNS. Statistical methods in medical research. Blackwell Science; 2002.

8. Bland M. Introduction to medical statistics. Oxford University Press; 2000.

9. UNAIDS. Report on the global HIV/AIDS epidemic; June 2000, 00.13E. 2000. www.UNAIDS.org.

10. Chenna R, Sugawara H, Koike T, Lopez R, Gibson TJ, Higgins DG, et al. Multiple sequence alignment with the Clustal series of programs. Nucl Acids Res 2003; 31:3497-3500.

11. Johnson VA, Brun-Vezinet F, Clotet B, Conway B, Kuritzkes DR, Pillay $\mathrm{D}$, et al. Update of the drug resistance mutations in HIV1: 2005. Top HIV Med 2005; 13:51-57.

12. de Oliveira T, Deforche K, Cassol S, Salminen M, Paraskevis D, Seebregts $\mathrm{C}$, et al. An automated genotyping system for analysis of HIV-1 and other microbial sequences. Bioinformatics 2005; 21:3797-3800.

13. Van Laethem K, De Luca A, Antinori A, Cingolani A, Perna CF, Vandamme AM. A genotypic drug resistance interpretation algorithm that significantly predicts therapy response in HIV. 1-infected patients. Antivir Ther 2002; 7:123-129. 
14. Rhee SY, Gonzales MJ, Kantor R, Betts BJ, Ravela J, Shafer RW. Human immunodeficiency virus reverse transcriptase and protease sequence database. Nucl Acids Res 2003; 31:298303.

15. Metzner KJ, Rauch P, Walter H, Boesecke C, Zollner B, Jessen H, et al. Detection of minor populations of drug-resistant HIV-1 in acute seroconverters. AIDS 2005; 19:1819-1825.

16. Schuurman R, Brambilla D, de Groot T, Huang D, Land S, Bremer $\mathrm{J}$, et al. Underestimation of HIV type 1 drug resistance mutations: results from the ENVA-2 genotyping proficiency program. AIDS Res Hum Retroviruses 2002; 18: 243-248.

17. Brenner BG, Routy JP, Petrella M, Moisi D, Oliveira M, Detorio $M$, et al. Persistence and fitness of multidrug-resistant human immunodeficiency virus type $\mathbf{1}$ acquired in primary infection. J Virol 2002; 76:1753-1761.

18. Delaugerre C, Morand-Joubert L, Chaix ML, Picard O, Marcelin AG, Schneider V, et al. Persistence of multidrug-resistant HIV-1 without antiretroviral treatment 2 years after sexual transmission. Antivir Ther 2004; 9:415-421.

19. Barbour JD, Hecht FM, Wrin T, Liegler TJ, Ramstead CA, Busch MP, et al. Persistence of primary drug resistance among recently HIV-1 infected adults. AIDS 2004; 18:16831689.

20. Bezemer D, de Ronde A, Prins M, Porter K, Gifford R, Pillay D, et al. Evolution of transmitted HIV-1 with drug-resistance mutations in the absence of therapy: effects on CD4+ T-cell count and HIV-1 RNA load. Antivir Ther 2006; 11:173178.

21. Wensing AM, van de Vijver DA, Angarano G, Asjo B, Balotta C,

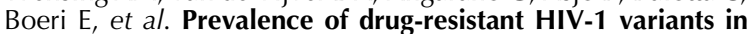
untreated individuals in Europe: implications for clinical management. J Infect Dis 2005; 192:958-966.
22. van de Vijver DA, Wensing AM, Angarano G, Asjo B, Balotta C, Boeri $\mathrm{E}$, et al. The calculated genetic barrier for antiretroviral drug resistance substitutions is largely similar for different HIV-1 subtypes. I Acquir Immune Defic Syndr 2006; 41:352-360.

23. Phillips A. Projection to 2010 of trends in multidrug resistant HIV in infectious gay men in the UK. In: Proceedings of the 13th Conference on Retroviruses and Opportunistic Infections (CROI); 2006; Denver. p. 649 [abstract].

24. Little SJ, Holte S, Routy JP, Daar ES, Markowitz M, Collier AC, et al. Antiretroviral-drug resistance among patients recently infected with HIV. N Engl J Med 2002; 347:385-394.

25. Grant RM, Hecht FM, Warmerdam M, Liu L, Liegler T, Petropoulos $\mathrm{CJ}$, et al. Time trends in primary HIV-1 drug resistance among recently infected persons. JAMA 2002; 288:181-188.

26. Shet A, Berry L, Mohri H, Mehandru S, Chung C, Kim A, et al. Tracking the prevalence of transmitted antiretroviral drugresistant HIV-1: a decade of experience. J Acquir Immune Defic Syndr 2006; 41:439-446.

27. Cane P, Chrystie I, Dunn D, Evans B, Geretti AM, Green H, et al. Time trends in primary resistance to HIV drugs in the United Kingdom: multicentre observational study. BMJ 2005; 331:1368.

28. Violin M, Cozzi-Lepri A, Velleca R, Vincenti A, D'Elia S, Chiodo $\mathrm{F}$, et al. Risk of failure in patients with 215 HIV-1 revertants starting their first thymidine analog-containing highly active antiretroviral therapy. AIDS 2004; 18:227-235.

29. Turner D, Schapiro IM, Brenner BG, Wainberg MA. The influence of protease inhibitor resistance profiles on selection of HIV therapy in treatment-naive patients. Antivir Ther 2004; 9:301-314.

30. Richman DD, Havlir D, Corbeil J, Looney D, Ignacio C, Spector $\mathrm{SA}$, et al. Nevirapine resistance mutations of human immunodeficiency virus type 1 selected during therapy. J Virol 1994; 68:1660-1666. 